\section{Timebomb: The Global Epidemic of Multi-Drug Resistant Tuberculosis}

\author{
by Lee B. Reichman with \\ Janice Hopkins-Tanne \\ McGraw-Hill, 320 pp, \$24.95 \\ ISBN: 0071359249,2001
}

cuss the global epidemic in depth, but rather focuses primarily on these two epidemics as indicators of the worldwide possibilities. These contrasting stories exemplify how in the modern world failure in one case makes success in the other far more difficult to achieve; for example, because some countries are failing to contain MDR strains of the disease, these strains are moving into countries that thought they had the situation in control.

In his account of the New York outbreak, Reichman traces the dismantling of TB public health programs not, as is typically asserted, to the Reagan administration's public health and economic policies, but to earlier policies of the Nixon and Ford administrations; he notes that epidemic and MDR TB occurred in New York City between 1972 and 1992. Eventually, through the heroic efforts of Margaret Hamburg, then New York City health commissioner, hundreds of dedicated public health workers and the expenditure of nearly one billion dollars, the epidemic was finally brought under control.

The chapters reviewing the TB epidemic in Russia are ominous, as we discover that in the new century, treatment of $\mathrm{TB}$ is still performed in the same style as at the turn of the last century. Although millions of dollars were available to help

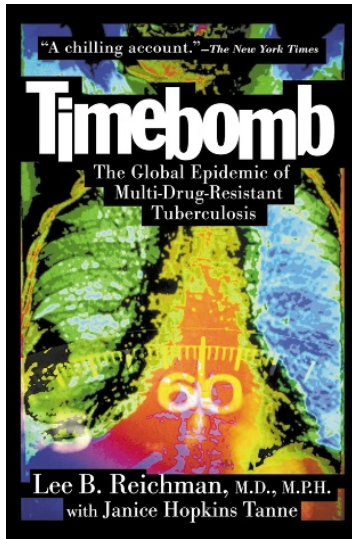

magnitudes worse once HIV appears on the scene. It is clear that the Russian public health system is on trial, and Reichman delivers a guilty verdict.

By comparing outcomes in New York City and Russia, Reichman spends a good deal of the book comparing right and wrong ways of combating epidemic TB: the right way the New York prison system handles prisoners and manages health care, and the wrong way the Gulag handles it; right treatment protocols that the World Health Organization has advocated based on a large and growing body of scientific evidence (that is, directly observed therapy) and wrong approaches Russia continues to use for treatment.

Like other recent works on the threat of infectious diseases such as Laurie Garrett's The Coming Plague, Timebomb has the power of fiction and it is sometimes easy to forget that it is not. Unlike the Garrett book, which is more a collection of short dramatic stories collectively telling a big picture about our coexistence and evolution with microbes, Reichman selects one story and presents it in novel form with better material than most science fiction. The book is organized in a clear and riveting manner. Early chapters follow the history of the disease, including diversions into the tragic lives of the Bronreform the current system at key TB treatment centers, Russian clinicians and scientists turned down this aid in order to preserve what they believe to be superior approaches, despite these not conforming to World Health Organization standards. This section of the book reads like a thrilling novel, and the reader is left as frustrated as the international scientists who are trying to intervene. Further, human conditions in the Russian Gulag prisons are ripe for the ballooning of MDR TB, and humanity and hope are lost there as well. Finally, HIV infection is a major cofactor of TB, and Reichman reminds us that the Russian TB epidemic will be orders of te sisters, Chopin and Henry David Thoreau, through whose deaths the disease acquired its romantic sheen. Clever chapter titles such as "Ebola with Wings" and subtitles like "A Difficult Dinner" add a sense of literary irony. Within the narrative style, the book is rich with up-to-the-minute details and references that add to its depth.

An incredible account of politics and disease dynamics occurring at all levels, Timebomb helps us realize that controlling or eradicating $\mathrm{TB}$ is not just about science and facts; likely if it were, TB would have long been relegated to the history books. 